\title{
A INTERDISCIPLINARIDADE NO ENSINO DE HISTÓRIA: RELAÇÕES POSSÍVEIS ENTRE A HISTÓRIA E A LITERATURA
}

Interdisciplinarity in History Teaching: possible relations between History and Literature

\section{Simone Garcia Almeida* Kassandra Thamyris Maciel Amador**1}

\begin{abstract}
RESUMO: $\mathrm{O}$ artigo busca pensar o ensino de História a partir de uma proposta interdisciplinar. Para tanto, as fontes literárias são consideradas importantes documentos a serem trabalhados pelo professor, já que contribuem para uma análise histórica sobre diferentes sociedades, seus costumes e sua cultura, o que pressupõe o conhecimento pelo professor das questões que envolvem a linguagem literária. Assim sendo, o objetivo geral deste trabalho é discutir a interdisciplinaridade no ensino de História, a partir do aporte da História e da Literatura. Com o intuito refletir sobre: a) literatura como fonte histórica; b) a problemática da História e da Literatura como formas de representar o passado; c) a itnterdisciplinaridade entre História e Literatura no campo do ensino, por essa razão desenvolvemos a pesquisa por meio de um estudo de revisão da literatura. Concluímos que a Literatura é uma forma de representação social e histórica, nesse sentido, o ensino de História por meio da utilização de fontes literárias poderá levar os alunos a refletirem sobre as experiências humanas, tais como: os hábitos, as atitudes, os sentimentos, as ideologias, as práticas e as inquietações que circulam em cada momento histórico e em diversas sociedades.
\end{abstract}

Palavras-chave: Ensino de História, interdisciplinaridade, História e Literatura, representações.

Abstract: The article discusses the teaching of history from an interdisciplinary perspective. To do so, the literary sources are considered as fundamental documents to be used by the teacher in classroom, contributing to a historical analysis of different societies, their customs and their culture. In order to reflect on literature as a historical source; the problems of History and Literature as diferente ways of representing the past; and the interdisciplinarity between History and Literature, we developed the research through a literature reviewing study. We assume that Literature is a form of social and historical representation, so, the teaching of History through the use of literary sources may lead students to reflect on human experiences.

\section{Introdução}

Pensar sobre o conceito de interdisciplinaridade e a sua importância ao estabelecer relações de diálogo e proximidade entre as disciplinas de História e Literatura é um dos pontos a ser analisado neste artigo. Tais relações podem ser discutidas no campo do ensino pela utilização de textos e obras literárias como material de apoio em sala de aula, por meio da prática de leituras e debate

\footnotetext{
* Doutora em História. Professora titular do curso de História da Universidade Federal do Amapá. E-mail: simonepgarcia@uol.com.br

** Graduada em História pela Universidade Federal do Amapá. E-mail: ksandramaciel@hotmail.com

${ }^{1}$ Conforme o estudo de FAZENDA, Ivani A. Integração e interdisciplinaridade no ensino brasileiro: efetividade ou ideologia. São Paulo: Loyola. 1979.
} 
entres alunos e professores. Dessa forma, as fontes literárias são consideradas importantes documentos a serem trabalhados pelo professor, já que contribuem para uma análise histórica sobre diferentes sociedades, seus costumes e suas culturas, o que pressupõe o conhecimento pelo professor das questões que envolvem a linguagem literária. Assim sendo, o objetivo geral deste trabalho é discutir a interdisciplinaridade no ensino de História, a partir do aporte da História e da Literatura.

Como objetivos específicos destacamos: a) problematizar a literatura como fonte histórica; b) refletir sobre a problemática da História e da Literatura como formas de representar o passado; e) pensar a interdisciplinaridade entre História e Literatura no campo do ensino. Além do mais, como principais questionamentos a serem problematizados podemos enfatizar: como pensar o ensino e pesquisa voltados para uma análise interdisciplinar? Como a Literatura pode contribuir para a renovação do ensino de História?

Desenvolvemos a pesquisa por meio de um estudo de revisão da literatura, assim sendo, o artigo é organizado em três partes: na primeira fizemos uma discussão sobre a problemática da interdisciplinaridade no ensino de História, destacando autores como Lima e Azevedo (2013), Pátaro e Bovo (2012), Bicudo (2008), Silva e Pinto (2009), Thiesen (2008) e Silva (2011); no segundo momento debatemos as relações que se estabelecem entre a História e Literatura, nesse sentido foram importantes as análises de Gaffo (2013), Borges (2010), Pesavento (1999, 2006, 2004), Chartie (1990, 2009), Le Goff (1990), Capraro (2014) e Cândido (2000); para finalizar abordamos a questão da interdisciplinaridade no ensino tendo como base as conexões entre a História e a Literatura. Vale ressaltar ainda que obras de Bitencourt (2004), Xavier e Cunha (s/d), Moraes (2009), Correia (2012), Garcia (2002), Almeida (2017), Benjamin (s/d) e Sevcenko (1989) foram fundamentais.

\section{1 - A interdisciplinaridade na pesquisa e no ensino de História}

Por entendermos que o conceito de interdisciplinaridade é amplo e possui várias interpretações e significados, vamos no ater nesse momento a uma ideia simples, de que a interdisciplinaridade se caracteriza como a interligação de saberes entre diferentes disciplinas e áreas de conhecimento. Esta interligação implica em um método de estudo e pesquisa que busca romper com as limitações trazidas por um modelo antigo: o modelo disciplinar, considerado tradicional, o qual consiste na delimitação do conhecimento em disciplinas isoladas e independentes.

Destacamos ainda um ponto importante: não podemos negar o papel considerável que a disciplinarização trouxe para a construção e desenvolvimento de estudos pertinentes em diferentes áreas do conhecimento. Sendo que foi a partir disto possível o debate para a implementação do modelo interdisciplinar, reiterando a necessidade de correlacionar diferentes áreas de saber e os estudos trazidos pelas disciplinas isoladas, para a ampliação do conhecimento.

Como considera Bicudo (2008, p.138), a qual ressalta a importância de compreendermos melhor a questão disciplinar para podermos pensar em como a interdisciplinaridade se constituiu, pois, para a autora fica claro que "é necessário analisar o contexto histórico da ciência hegemônica no mundo ocidental na época moderna, e pontuar o que passa a incomodar os estudiosos quanto ao sentido que devem seguir seus princípios e métodos de investigação.” Destaca ainda:

A interdisciplinaridade faz corresponder resultados, diante de um objeto investigado, mescla métodos e, ao avançar, termina por identificar outros objetos de estudo, acabando, muitas 
vezes, por tornar-se uma nova disciplina, voltando ao modelo disciplinar. Esse modo de proceder teve um bom desenvolvimento no século XIX, dando origem a novos campos de estudo como os da neurofisiologia, físico-química, dentre outros (2008, p.141-142).

Bicudo (2008) enfatiza que para responder aos novos temas e problemáticas do mundo contemporâneo, faz-se necessário uma postura que consiga perceber as articulações possíveis e dinâmicas que se estabelecem entre as diferentes disciplinas, abandonando a postura de compreendê-las como seres estanques. A autora deixa claro que isso não significa abandonar os conteúdos disciplinares e seus procedimentos, que durante séculos foram bem sucedidos, apenas que problemáticas diversas solicitam do pesquisador procedimentos que ultrapassam o limite meramente disciplinar.

Silva e Pinto (2009) entendem, ainda, que essa reconfiguração nas práticas disciplinares cobra também uma mudança no perfil do pesquisador, enquanto sujeito que constrói conhecimento, bem como na própria escola, haja vista que, novas habilidades e competências são exigidas, tanto para o desenvolvimento da ciência, como para o mundo do trabalho. Com relação a interação entre as disciplinas no campo educacional, Lima e Azevedo (2013) destacam² que Guy Michaud propõe quatro níveis para esse diálogo:

[...] a multidisciplinaridade, que pressupõe a justaposição de disciplinas, sem, contudo, diminuir o "status" de cada uma delas; a pluridisciplinaridade, que seria a justaposição de disciplinas de áreas comuns; a interdisciplinaridade, interação entre disciplinas direcionadas por um coordenador e que pode ocorrer como uma simples comunicação de ideias ou como uma integração mútua de conceitos/métodos/objetos; e a transdisciplinaridade, que funcionaria como um axioma comum às disciplinas (p. 130-131).

Para o nível interdisciplinar Lima e Azevedo (2013, p.131) esclarecem que Ivani Fazenda identifica quatro variações:

[...] a Inter Heterogênea, que seria uma visão geral não aprofundada da temática a ser trabalhada pelos professores e suas respectivas disciplinas, mantendo, assim, certo distanciamento e limites entre as mesmas; a Psendo Interdisciplinaridade, que seria o uso dos mesmos instrumentos de análise sobre um tema norteador, mas sem haver a real aproximação das disciplinas; a Inter Complementar, que seria o agrupamento das disciplinas com o intuito de complementação dos domínios de estudo de uma determinada área de conhecimento; e, por último, a Inter Unificadora, que se basearia em uma coerência na integração teórica e metodológica.

Percebemos, dessa forma, que os caminhos para alçar a interdisciplinaridade são variados, o que conforme Pátaro e Bovo (2012) explicaria os diferentes entendimentos sobre o conceito, inferindo nas diversas perspectivas possíveis de construção de um trabalho científico interdisciplinar.

Pacheco; Tosta e Freire (2010), no entanto, entendem que, mesmo que exista uma diferenciação quanto as terminologias variáveis deste conceito e suas diversas definições, o que deve ser levado em conta é justamente a integração entre as disciplinas. Assim “(...) a interdisciplinaridade se caracteriza pela intensidade das trocas entre os especialistas e pelo grau de integração real das disciplinas, no interior de um projeto específico de pesquisa". (p.140).

${ }^{2}$ Conforme o estudo de FAZENDA, Ivani A. Integração e interdisciplinaridade no ensino brasileiro: efetividade ou ideologia. São Paulo: Loyola. 1979. 
Vale destacar ainda a discussão de Lima e Azevedo (2013), os quais reiteram que para construir um projeto interdisciplinar é preciso compreender os atributos, apontados por Fazenda, como próprios do perfil interdisciplinar: o respeito, a afetividade e a humildade. Pois, as autoras acreditam que "os envolvidos em ações interdisciplinares precisam estar prontos para a resolução de conflitos, embates de ideias e aceitação do outro. Não basta pensar, é preciso fazer-se e sentirse interdisciplinar." (p. 132). Nesse sentido, o historiador (pesquisador e professor) deve ser preparado para lidar com as questões, problemas e conflitos que o trabalho interdisciplinar cobra, seja no debate acadêmico dentro das universidades, seja no ambiente escolar do ensino básico.

No Brasil a questão da interdisciplinaridade foi pensada e inserida nas legislações educacionais, implementadas recentemente para a formação e fortalecimento da educação básica no país. Nesse sentido, foram criadas leis e parâmetros curriculares que abarcam a interdisciplinaridade como elemento essencial na promoção de uma educação básica de qualidade, exemplificando isto, houve em 1996 a institucionalização da Lei de Diretrizes e Bases da Educação Nacional - LDBN e em 1998 os Parâmetros Curriculares Nacionais - PCN. Destacamos que esta nova legislação buscou integrar a realidade do aluno à forma de aprendizagem dentro da escola, levando em consideração suas necessidades, vivências e experiências. Esse é um aspecto muito importante a ser considerado, pois, como afirmam Pátaro e Bovo (2012, p.52):

Sabemos que muitas vezes, no interior da escola, as disciplinas curriculares são tomadas de maneira desvinculada da realidade e dos problemas vividos em nossa sociedade contemporânea. Quando isso ocorre, as disciplinas e seus conteúdos passam a ser a base de aulas que se limitam a transmitir conhecimentos prontos que, quando isolados uns dos outros, podem não oferecer respostas aos problemas atuais da sociedade - que são complexos e exigem a colaboração de várias áreas do saber humano para serem percebidos e compreendidos.

O ensino de História nos PCN é pensado de maneira integrada com as amplas possibilidades de fontes e conhecimentos trazidos por outras disciplinas e conteúdos e, também, vem reforçando a importância da contextualização dos assuntos tratados. Para isso, propõe a divisão dos seus conteúdos, no ensino fundamental em eixos temáticos, o que favorece assim a aplicação de uma postura de ensino interdisciplinar. Já tratando mais especificamente sobre as metodologias interdisciplinares, os PCN trouxeram como um de seus temas o volume intitulado "Temas Transversais" pensado justamente para tratar sobre a interação de disciplinas no aprendizado escolar.

Outra discussão pertinente é de Pátaro e Bovo (2012, p.58), os quais propõem algumas metodologias interdisciplinares e transversais para o trabalho de pesquisa e ensino, uma delas é a: construção de projetos nas escolas e de metodologias de Aprendizagem Baseada em Problemas ABP. Essa prática possibilitaria a interação entre alunos e professores, além de um debate mais participativo voltado para a resolução de questões próprias e cotidianas, favorecendo a integração entre escola e a realidade dos alunos.

Aliás, destaca-se a respeito da necessidade da formação para o trabalho interdisciplinar. Porque, as universidades são reconhecidamente locais de produção de conhecimento e são elas que devem se tornar a porta de entrada para a produção interdisciplinar, assim como de se tornarem as responsáveis pela formação de seus acadêmicos em profissionais preparados para as demandas que a interdisciplinaridade exigirá, ou seja, são nas universidades que esta formação necessita ser pensada e discutida. Pacheco; Tosta e Freire (2010, p.146) entendem que a interdisciplinaridade nas universidades tem a função de: 
[...] ser a ponte entre as disciplinas, determinando que existam espaços livres para se beber de outros saberes sem que se precise negar totalmente a essência das crenças e valores paradigmáticos disciplinares. Ou seja, a interdisciplinaridade é uma carta de alforria para os professores, pesquisadores e alunos poderem passear pelos conceitos e metodologias de diferentes disciplinas que os permitam conhecer outras visões de mundo.

Um dos questionamentos que devemos fazer quanto à possibilidade de efetivação de um ensino interdisciplinar é pensar se o professor está preparado para esta interação com outras disciplinas, levando em consideração as experiências trazidas por seus alunos para a sala de aula. Entendemos que é preciso mudanças na formação de professores e isto deve partir de dentro das universidades. Elas precisam se mostrar capazes de debater e incentivar uma formação acadêmica mais ampla e voltada para a interdisciplinaridade. Thiensen (2008) afirma que:

De todo modo, o professor precisa tornar-se um profissional com visão integrada da realidade, compreender que um entendimento mais profundo de sua área de formação não é suficiente para dar conta de todo o processo de ensino. Ele precisa apropriar-se também das múltiplas relações conceituais que sua área de formação estabelece com as outras ciências (...) ao educador caberá o papel de reconstruí-lo dialeticamente na relação com seus alunos por meio de métodos e processos verdadeiramente produtivos. (p. 551-552).

Como metodologia de ensino é importante que o professor incentive junto aos seus alunos a problematização de temas apresentados em sala de aula, além disso, possibilite que os alunos criem a prática de contextualizar os assuntos tratados e debatidos. Assim, o processo de ensinoaprendizagem é dinamizado, incentivando o aluno a pensar os temas e assuntos abordados em sala de aula por meio de várias perspectivas e abordagens. Esse aspecto é apontado por Lima e Azevedo (2013), em que caracterizam o perfil do professor interdisciplinar o qual deve:

[...] ter gosto pelo conhecer e pesquisar, ter um comprometimento diferenciado para com os alunos, usar novas técnicas e procedimentos de ensino. Em outros termos, ser interdisciplinar implicaria em um ir além do simples trabalho em conjunto, seria necessário mudar hábitos, métodos e recursos, talvez por isso, haja resistência de professores quanto ao trabalho interdisciplinar. (p. 130).

É necessário também pensar que "o diálogo entre professores precisa ser estreitado para que haja cooperação no trabalho pedagógico que se quer interdisciplinar” (SILVA, 2011, p.602). Só assim é possível a promoção de projetos interdisciplinares e efetivá-los corretamente nas escolas.

A partir desse contexto, a implantação de um ensino interdisciplinar requer muitos esforços para que seus resultados sejam positivos e possam promover uma integração escolar satisfatória. Isso demanda tempo, investimento, vontade e incentivo, tanto por parte de professores, alunos, pais, quanto dos coordenadores pedagógicos e secretarias de educação. Muitas discussões ainda precisam ser feitas e projetos educacionais devem ser pensados em conjunto entre toda a comunidade escolar, para que se possibilite uma educação e um ensino verdadeiramente interdisciplinar nas escolas.

\section{2 - As relações entre a História e a Literatura}

Com a ampliação da noção de fonte histórica a partir das propostas da Escola dos Annales, o historiador incorporou em sua atividade de pesquisa uma gama de materiais, integrando ao seu 
campo de estudo diversas linguagens, tais como: literatura, relatos, cinema, teatro, música, pinturas, fotografias, etc. Neste sentido, o historiador tem questionado a própria relação da História com essas linguagens, como salientam Vieira, Peixoto e Khoury (2007, p. 20-21):

Ao trabalhar com outras linguagens, é preciso coloca-las como elementos constitutivos da realidade social.

A identidade social não é anterior às linguagens pois estas são partes constitutivas daquelas. Isso porque, não apenas expressam e especificam o social, mas a identidade social é constituída também pelas linguagens (...)

A literatura, dessa forma, expressa relações sociais propostas e, ao mesmo tempo, modelas formas de agir e pensar. É um objeto privilegiado para alcançar mudanças não apenas registradas na literatura, mas, principalmente, mudanças que se transformaram em literatura pois, mais do que dar um testemunho, ela revelará momentos de tensão. Ela pode expressar possíveis não realizados.

Deste modo, novas fontes de pesquisa começaram a ser utilizadas e novos métodos de análise se consolidaram para a análise histórica. Gaffo (2013, p.02) evidencia que:

Os historiadores (...) passaram a atentar para a sociedade atingindo seus aspectos sociais, políticos, econômicos e culturais. Passaram também a se dedicar a investigar o homem em sua complexidade, não apenas o que ele deixou registrado em documentos oficiais, mas também o que deixou de relevante para a análise de seus aspectos mentais. $\mathrm{O}$ foco de abordagem passou a ser o ser humano que vivia à margem, não só as grandes personalidades históricas mereciam destaque, mas sim aquele que vivia a história de quem foi vencido e não apenas os que venceram.

A literatura como documento possibilita identificar as características e intencionalidades dos sujeitos históricos de uma sociedade em diferentes épocas. Visto que, apresentam aspectos sociais múltiplos e subjetividades que nos possibilitam extrair informações pertinentes para a análise historiográfica, além de nos colocar frente a outras formas de análise, tornando a pesquisa histórica interdisciplinar e variada (BORGES, 2010).

\section{1 - Veracidade e ficção na História}

Uma questão bastante discutida está relacionada justamente à veracidade dos discursos históricos que se baseiam em fontes literárias. Porém, a questão que surge daí é "a História é de fato uma narrativa verdadeira?" Pesavento (1999, p. 819) entende que: "Dizer que a história é uma narrativa verdadeira, de fatos acontecidos, com homens reais, não é, entretanto, afirmar que, como narrativa, ela seja mimese daquilo que um dia teria ocorrido.” Significa dizer que, a História não busca fazer uma reconstrução idêntica dos fatos tal qual se deram no passado, na verdade, buscase apresentar os fatos acontecidos a partir do que nos é informado pelas fontes. Desta forma, o historiador com base nessas fontes nos apresenta uma representação desse passado.

Por essa perspectiva, o uso de obras literárias como fontes históricas passou por um período de questionamentos, desconfianças e até rejeição por parte de alguns estudiosos, justamente pelas críticas que se faziam quanto à veracidade e credibilidade dos fatos e da narrativa literária, que era compreendida como uma narrativa ficcional, pouco relacionada ou preocupada com questões históricas reais. Como Pesavento (1999, p.820) frisa que: 
A questão da veracidade e da ficcionalidade do texto histórico está, mais do que nunca, presente na nossa contemporaneidade, fazendo dialogar a literatura e a história num processo que dilui fronteiras e abre as portas da interdisciplinaridade. O texto histórico comporta a ficção, desde que o tomemos na sua acepção de escolha, seleção, recorte, montagem, atividades que se articulam à capacidade da imaginação criadora de construir o passado e representá-lo. Há, e sempre houve, um processo de invenção e construção de um conteúdo, o que, contudo, não implica dizer que este processo de criação seja de uma liberdade absoluta. A História, se a quisermos definir como ficção, há de se ter em conta que é uma ficção controlada. A tarefa do historiador é controlada pelo arquivo, pelo documento, pelo caco e pelos traços do passado que chegam até o presente. De uma certa forma, eles se "impõem" ao historiador, que não cria vestígios do passado (no sentido de uma invenção absoluta), mas os descobre ou lhes atribui um sentido, conferindo-lhe o estatuto de fonte.

Sobre o termo "ficção controlada" utilizado por Pesavento (1999, p.820) ao se referir a narrativa histórica, ela esclarece: "Ficção controlada porque a História aspira a ter, em sua relação de 'representância' com o real, um nível de verdade possível. Se não mais aquela verdade inquestionável, única e duradoura, um regime de verdade que se apoie num desejável e íntimo nível de aproximação com o real."

Chartier (2009) discute a relação entre a história e a ficção, afirmando que a diferenciação entre as duas tem se mostrado vacilante, mas compreende que a história realiza "uma representação adequada do real" e que a literatura (entendida como ficção) é "um discurso que informa do real, mas não pretende abonar-se nele." Nesse sentido, a Literatura busca se apoderar de fatos e personagens históricos os colocando em situações que foram reais ou apresentadas como tais, ela também se apropria de documentos e técnicas da disciplina histórica, como um dispositivo que cria um "efeito de realidade", destinado a carregar a ficção literária de um peso de realidade. Percebese assim uma aproximação entre as diferentes disciplinas, isto é, uma busca de outros aspectos e pontos para fortalecer seus discursos e histórias (CHARTIE, 2009, p.24-25, p.27-28).

\section{2 - Representação e memória na Literatura}

Chartie (1990) conceitua representação em dois sentidos: primeiro, como a imagem presente de um objeto ausente, mantendo, portanto, uma relação de substituição com o objeto representado; e em segundo lugar a exibição pública de algo existente. Assim, representação é a manifestação de uma ausência ou de uma presença.

As definições antigas do termo [representação] (...) manifestam a tensão entre duas famílias de sentidos: por um lado, a representação como dando a ver uma coisa ausente, o que supõe uma distinção radical entre aquilo que representa e aquilo que é representado; por outro, a representação como exibição de uma presença, como a apresentação pública de algo ou alguém. No primeiro sentido, a representação é instrumento de conhecimento mediato que faz ver um objeto ausente através de sua substituição por uma "imagem" capaz de reconstruir em memória e de o figurar tal como ele é (CHARTIE, 1990, p. 20)

A partir do exposto, verificamos que o processo de representar, tanto na História como na Literatura, ou seja, na ficção, implica em reconhecer que há um esforço de interpretar e compreender o mundo em que vivemos. Nessa perspectiva, Pesavento (2006, p.01) faz uma discussão sobre o conceito de "imaginário", considerado muito importante para a compreensão da Literatura, pois para ela: "o imaginário é sempre um sistema de representações sobre o mundo, que se coloca no 
lugar da realidade, sem com ela se confundir, mas tendo nela o seu referente".

Entendemos que a Literatura trabalha com a construção de representações: de tempo, de espaço, de sujeitos, entre outras. Por essa razão, Grecco (2015, P. 120) percebe as representações como extremamente significativas, "já que é a partir delas que as sociedades observam a realidade e definem a sua existência." Para ela:

[...] a aproximação entre História e Literatura amplia novos paradigmas interpretativos. Nesse sentido, os discursos literários, ao resgatarem temas históricos, operam seletivamente, assegurando um novo olhar sobre os fatos, reinterpretando-os (...) tanto a Literatura como a História, portanto, contribuem para a construção de uma identidade social e individual. Ambas traduzem uma sensibilidade na apreensão da realidade e operam oferecendo leituras diversas. (p. 122).

Nesse sentido, entendemos que tanto o texto histórico quanto o texto literário são capazes de construir um discurso de representatividade agregador os quais possibilitam a socialização de ideias. Nessa mesma linha de pensamento, Moraes (2009) ressalta que:

Diferentemente da narrativa histórica estruturalista, ou da narrativa didática, que, muitas vezes, trabalha com seres genéricos - o operário, a classe dominante, os burgueses -, a literatura constrói, a partir do conceito de representação, personagens com identidade, profundidade, memória, ações, como se fossem de carne e osso. (p. 07).

A obra literária, então, é percebida como uma manifestação cultural que pode dizer muito sobre a sociedade a qual pertence ou retrata e caberá ao historiador assumi-la como fonte de pesquisa, já que toda a obra ficcional está inscrita em um tempo e espaço específicos, expressando as condições sociais nas quais foi produzida, expressando assim, além da realidade, sonhos, desejos e utopias.

Grecco (2015) vai destacar também as relações que a Literatura estabelece com a memória, pois se por um lado não tem uma preocupação explícita com ela, por outro permite apreender aspectos da memória coletiva. Desta forma, as fontes literárias auxiliam grandemente na compreensão e identificação de contextos históricos vividos justamente por meio das representações descritas nas obras literárias.

Porém, é importante frisar, como nos lembra Sena Júnior (s/d, p.8) que as representações propostas pela literatura não são o reflexo do real, mas sim representações historicamente construídas “(...) que colocam em campo forças que se relacionam e definem o imaginário acerca do real como construção social." Por esse ângulo, ao lermos uma obra literária devemos buscar as representações que ela comporta, na tentativa de compreender as suas imagens e metáforas e o porquê de assim estarem colocadas, não devemos tomar essas representações como simplesmente verdades inquestionáveis prontas e acabadas.

Nesse sentido, identificamos a necessidade de uma formação mais complexa do profissional de história. Tanto os pesquisadores, como os professores necessitam perceber as fontes literárias como possibilidade para o trabalho historiográfico, porque são muito ricas para a compreensão da História Social.

\subsection{Literatura: texto e contexto}

Tendo em vista que tanto a narrativa histórica como a ficcional constroem representações 
sobre a sociedade, Pesavento (2004) ressalta que há uma tríade que deve ser considerada pelo historiador quando da produção do conhecimento histórico, a qual tem por base: a escrita ou produção do texto, em que o historiador volta-se para saber sobre quem fala, de onde fala e que linguagem é utilizada; o texto nesse momento é importante, por compreender o que se fala e como se fala; e por fim, a leitura (recepção) em que visa abordar a leitura de um determinado receptor ou de um grupo deles, tratando das expectativas de quem recebe o texto, de sua contemplação, seja pelo seu enfrentamento, seja pela sua resistência.

A partir da concepção de Le Goff (1990, p. 545) sobre o documento como monumento, "produto da sociedade que o fabricou segundo as relações de força que detinham", demonstra a conveniência da realização pelo historiador, de uma análise sobre as condições históricas dessa produção, já que o documento não é inócuo. Assim, tal análise envolve: o produtor, o lugar social de onde se dá a produção e como é produzida; as intensões do produtor, as relações de poder que alcançaram a produção e o produto. Como destaca Borges (2010, p. 95) "se todo o documento é monumento, cabe ao historiador desvendar como foi construído, a linguagem utilizada, a finalidade da edificação e as suas intencionalidades".

Contextualizar a fonte, portanto, é indispensável, por um lado, por outro não esquecer a perspectiva que a literatura é obra de arte e, neste sentido, compreender seu estilo e sua linguagem são importantes. A partir disso, Antônio Cândido em Literatura e Sociedade propõe um contraponto entre os autores que entendem a Literatura unicamente como fonte, no sentido de que permitem o acesso a um determinado contexto histórico e, outros, principalmente, críticos literários que negam o aspecto social da obra, enfatizando que a Literatura só pode ser analisada por meio de critérios estéticos. Vejamos:

Hoje sabemos que a integridade de uma obra não permite adotar nenhuma dessas visões dissociadas; é que só a podemos entender fundindo texto e contexto numa interpretação dialeticamente íntegra, em que tanto o velho ponto de vista que explicava pelos fatores externos, quanto o outro, norteado pela convicção de que a estrutura é virtualmente independente, se combinavam como momentos necessários do processo interpretativo. Sabemos, ainda, que o externo (no caso, o social) importa, não como causa, nem como significado, mas como elemento que desempenha um certo papel na constituição da estrutura, tornando-se portanto, interno. (CANDIDO, 2000, p. 4)

Portanto, quando olhamos para uma obra literária devemos procurar compreendê-la tanto a partir do fator interno, ou seja, as temáticas abordadas, suas tramas, como o autor compreende e representa a temática, sua dimensão formal e estética, quanto a partir do fator externo, isto é, o contexto social e temporal no qual a obra se insere. Sendo assim, é “(...) função do pesquisador compreender como tal contexto social foi incorporado pelo autor e manifestado esteticamente na sua produção artística/literária (CAPRARO, 2014, p. 4).

Evidenciamos que a utilização de fontes literárias requer um trabalho dinâmico e interdisciplinar, tanto para a pesquisa quanto para o ensino de História, já que a Literatura, como uma disciplina voltada para o campo das artes, traz em sua formação aspectos próprios, amplos e diferenciados para a análise historiográfica, que auxiliam na criação de novos métodos de abordagem e interação com História. Abre-se um novo canal de busca por conhecimento histórico.

A pesquisa e o ensino por meio da interação entre História e Literatura propiciam um melhor aprendizado sobre as questões cotidianas do passado e do presente, pois possibilitam uma 
reflexão interdisciplinar e contextualizada, trazendo novas abordagens e debates tanto nos trabalhos de pesquisa como e, principalmente, na sala de aula.

\section{História e Literatura: a interdisciplinaridade no ensino}

O que propomos neste artigo é pensar o uso das fontes literárias no ensino de História, a partir de um ensino interdisciplinar que possibilite a interação entre a disciplina de História com outras disciplinas e áreas de conhecimento, como a própria Literatura e a Língua Portuguesa. Por entender que a prática de análise interdisciplinar facilita a apreensão e produção de conhecimento, acreditamos ser de grande relevância o uso de obras literárias no ensino de História, porque possibilita explorar junto aos alunos a capacidade que têm de interpretar e correlacionar as tramas literárias com os fatos históricos e seus sujeitos.

Conforme Circe Bittencourt (2004), os documentos escritos, entre eles a Literatura, podem ser utilizados: 1) simplesmente como ilustração para servir de reforço a uma ideia expressa pelo livro didático ou pelo professor ao desenvolver um conteúdo; 2) como fonte de informação explicitando uma situação histórica, etc; 3) para introduzir um tema de estudo, assumindo assim a condição de situação problema, para que o estudante identifique o objeto de estudo ou o tema a ser pesquisado. Também Xavier e Cunha (s/d, p. 639) analisam o trabalho com as fontes históricas no ensino de História:

As fontes históricas ao serem remetidas no auxílio da produção do conhecimento em história, na prática de sala de aula, tornam-se ferramentas culturais. As fontes históricas não devem ser simplificadas a uma mera ilustração de conteúdos, uma vez que se traduzem em artefatos culturais repletos de intencionalidades. As fontes devem assumir um papel fundamental de significação na estrutura cognitiva do aluno: demonstrar as representações que determinados grupos forjaram sobre a sociedade em que viviam como pensavam ou sentiam, como se estabeleceram no tempo e no espaço; como servir para que o aluno seja capaz de fazer diferenciações, abstrações que o permitam fazer a leitura das distintas temporalidades as quais estamos submetidos.

Compreendemos, portanto, que as fontes históricas devem ser operacionalizas como algo que vá além de meras lustrações, mas como uma "ferramenta psicopedagógica que poderá certamente auxiliar o professor na difícil tarefa de estimulação do imaginário do aluno na aprendizagem da história." (XAVIER; CUNHA, s/d, p. 641). Porém, "a utilização das fontes histórica não trata de buscar as origens ou a verdade de tal fato, trata-se de entender estas enquanto registro testemunhos dos atos históricos." (XAVIER; CUNHA, s/d, p. 644).

Destarte, a Literatura é entendida como uma fonte auxiliadora para se compreender os acontecimentos históricos, para o presente trabalho buscamos identificar as interpretações que são feitas com base nas representações vistas no texto literário voltada para o campo do ensino de História. Haja vista que pelo texto literário ter diversas funções, o ensino por meio da Literatura pode torná-lo mais lúdico, interativo e dinâmico, propiciando um aprendizado sobre os assuntos históricos mais eficiente e produtivo.

Esclarecemos, ainda, que a intensão do professor, ao trabalhar com documentos em sala de aula, não é transformar o aluno em pequeno historiador, como bem enfatizou Bitencourt (2004), pois o objetivo é desenvolver a autonomia intelectual dos estudantes, possibilitando fazer análises críticas da sociedade em uma perspectiva temporal e espacial. 
O professor traça objetivos que não visam à produção de um texto historiográfico inédito ou a uma interpretação renovada de antigos acontecimentos com o uso de novas fontes. As fontes históricas em sala de aula são utilizadas diferentemente. Os jovens e as crianças estão "aprendendo História" e não dominam o contexto histórico em que o documento foi produzido, o que exige sempre a atenção ao momento propício de introduzi-lo como material didático e à escolha dos tipos adequados ao nível e às condições de escolarização dos alunos (BITENCOURT, 2004, p. 329).

\section{1- Pensando a interdisciplinaridade entre História e Literatura a partir de duas propostas desenvolvidas no ensino superior.}

Antes de apresentamos as propostas das professoras Moraes (2009) e Almeida (2017), é importantes destacarmos a colocação de Correia (2012), que pontua a ampliação dos objetos de estudo, dos temas, dos problemas e das fontes que passam a ser utilizados em salas de aula. Explicita algumas questões que devem ser consideradas:

O texto literário, tratado como fonte histórica, requer que se façam os questionamentos necessários tais como: Quem é o autor? Qual o seu público? A quem se destina a obra? Em que momento histórico foi criado? Qual a importância desta obra nos dias atuais? Perguntas essenciais para se iniciar um trabalho interdisciplinar envolvendo a Literatura no ensino de História. (p. 192-193).

Fica evidente a necessidade de questionemos a fonte literária e que possamos analisá-la juntamente com outros textos referenciais que nos auxilie na interpretação e investigação histórica. É o que se entende por contextualizar e problematizar a fonte, para assim alcançarmos as mudanças e permanências de uma determinada sociedade

A professora Dislane Moraes (2009) elaborou um projeto intitulado "O texto literário e o ensino de história: uma análise das crônicas de Stanislaw Ponte Preta”, envolvendo História e Literatura, para ser aplicado com seus alunos do curso de História da Universidade do Ibirapuera, destacando que a intenção foi desenvolver a consciência e o pensar histórico dos acadêmicos, para que pudessem correlacionar os fatos históricos com o relato literário.

Com esta metodologia procurava-se desenvolver algumas noções e conceitos específicos para a construção da consciência histórica, uma aprendizagem que favorecesse a incorporação do pensar histórico, ou, em outras palavras, a inclusão da dimensão temporal como elemento importante na organização do pensamento e nas escolhas e decisões da vida cotidiana. De modo bem sintético esperava-se abordar as noções de processo histórico, agentes sociais, múltiplas temporalidades, imaginação histórica e valor da narração no processo cognitivo. Isto é, propiciar a habilidade de voltar-se para o passado, compreender o "outro" em "outro tempo", e perceber as relações entre o passado e o presente, além de aspectos relacionados à construção de memórias (nacional, de grupos e individuais). (MORAES, 2009, p.02).

Sobre a metodologia aplicada em seu projeto, ela descreve:

[...] desenvolvemos uma atividade de seminários sob título de História do Brasil através da Literatura. Indicávamos a leitura de uma obra literária e de um texto de apoio da área de história ou de análise literária. Os alunos eram orientados a estabelecer comparações entre os textos e a elaborar questões relacionadas ao conhecimento histórico que porventura tivessem adquirido com a leitura do texto literário. (p.02). 
Assim sendo, devemos pesquisar uma obra que traga questões histórias possíveis de se identificar e analisar em sala e, também, ter outros textos que sirvam como material de apoio para as discussões e embasamento dos argumentos e das questões apresentadas. Para a aplicabilidade dessa metodologia, Moraes (2009, p. 02) especificou algumas orientações:

(...) Resumo do enredo e análise de personagens e situações escolhidas; levantamento de dados biográficos do autor e do contexto histórico e da história literária relativa à produção dos textos; interpretação do modo como os fatos históricos são representados na ficção; comparação com as narrativas historiográfica e literária sobre o mesmo tema.

Moraes (2009) concluiu que o desenvolvimento da atividade possibilitou por parte dos alunos a reflexão sobre a especificidade do discurso historiográfico, a diferença entre documentos históricos e a narrativa do historiador e, por fim, a compreensão da dimensão narrativa do ato de interpretação.

Outro ponto levantado pela autora que pode exemplifica a necessidade de um ensino interdisciplinar é quanto a uma das características do texto literário que deve ser levado em conta: a forma de linguagem. "Para se compreender bem um texto literário é preciso decifrar os recursos de linguagem usados pelo escritor: o uso de metáforas, alegorias, construções de personagens e efeitos retóricos. Esses elementos são fundamentais para se perceber as dimensões históricas de um texto" (MORAES, 2009, p. 04).

Nesse momento que se faz importante a complementariedade de disciplinas, pois, a questão da linguagem necessita de uma análise mais ampla e a disciplina de Língua Portuguesa deve ser utilizada e buscada para integrar o debate e auxiliar no ensino de História. Percebemos a busca de Moraes (2009) pelos caminhos propostos pela interdisciplinaridade, por integrar assuntos históricos, literários e linguísticos numa mesma proposta de ensino, o qual favorece a discussão sobre os fatos históricos presentes no enredo literário.

Simone Garcia Almeida, professora da Universidade Federal do Amapá, vem desenvolvendo desde 2017, o projeto "A representação do negro na literatura brasileira: caminhos para uma discussão sobre educação antirracista", que articula ensino, pesquisa e extensão, seguindo as mesmas diretrizes indicadas por Moraes (2009) e Correia (2012). A proposta é fazer um estudo envolvendo Educação, História e Literatura, partindo da luta dos negros no Brasil para que a sua história fosse ensinada nas escolas de forma positiva, e que possibilitasse apontar para a importância do negro na constituição de nossa sociedade, desmistificando o mito da democracia racial muito presente nos currículos escolares.

Nesse sentido, as intensões de Simone Garcia Almeida são: 1) discutir a problemática do currículo escolar a partir da análise de Lei 10.639/03, que alterou a Lei de Diretrizes e Bases da Educação Nacional (Lei 9.394/96), estabelecendo a obrigatoriedade do ensino de história e cultura afro-brasileira e africanas na educação básica; 2) analisar como o negro vem sendo representado na literatura brasileira, propondo um trabalho interdisciplinar entre a Literatura e a História, para desconstruir o discurso elaborado sobre o negro, por um lado e, por outro, discutir a própria representação construída por ele na chamada Literatura Negra ou afro-brasileira; 3) introduzir o aluno ao trabalho com documentos, especialmente, fontes escritas e de caráter literário. Sendo o objetivo principal, a partir dessa discussão, de um trabalho de extensão nas escolas: realizar uma reflexão sobre a realidade do negro em nossa sociedade, desmistificando diversos estereótipos construídos sobre a figura do negro no Brasil. 
As atividades em torno do projeto foram divididas em três fases: na primeira foram desenvolvidas as discussões teóricas em torno da problemática de educação antirracista; na segunda a análise e discussões da representação do negro na literatura brasileira, para tanto essa fase foi dividida em dois momentos: o primeiro se deu por meio da leitura dos textos teóricos sobre as relações entre a História e a Literatura; a representação do negro na Literatura brasileira, especialmente, no Romantismo e Naturalismo e sobre a constituição de uma literatura negra ou afro-brasileira; o segundo a leitura dos romances: "Escrava Isaura" de Bernardo Guimarães, "O Tronco do Ipê" de José de Alencar, representativos do Romantismo Brasileiro e "O Mulato" de Aluízio Azevedo, característico do Naturalismo e quatro obras da Literatura Negra: "Sobre as Vitórias que a História não Conta" de André Luiz Soares, "Sina Traçada" de Custódia Wolney, "Água de Barrela" de Eliana Alves dos Santos Cruz, "Haussá 1815 - Comarca de Alagoas" de Júlio César Farias de Andrade, essas últimas por sua vez venceram o prêmio Oliveira Silveira promovido de Fundação Cultural Palmares em 2015.

Desse modo, buscou-se na leitura dos romances identificar o lugar social dos autores das obras, sua linguagem, seus receptores, ou seja, a tríade proposta por Pesavento (2004): a escrita, o texto e leitura (recepção) e, detalhadamente, discutir as representações construídas em torno da figura do negro em diferentes momentos históricos. Por fim, a terceira fase, na qual foram elaborados banners para a exposição dos resultados da atividade em escolas de ensino fundamental.

Lembramos que os projetos de Moraes e Almeida têm como público alvo estudante do ensino superior, ou seja, foram voltados para a formação dos futuros profissionais de História. As propostas foram pensadas, justamente, pela inquietação das duas autoras com a dificuldade e a falta do hábito de leitura pelos alunos. Entendem que a integração entre História e Literatura, em um projeto de ensino, contribui para o fortalecimento e a construção do conhecimento e defendem a utilização de textos literários nas aulas de História, pois identificam nas obras literárias as possibilidades de reforçar junto aos seus alunos a capacidade de crítica, análise, comparação e interpretação.

\section{3- Literatura: a História dos possíveis}

Verificamos que com a crise do positivismo, a ideia de que a História relata aquilo que "realmente aconteceu", não é verdadeiro, no sentido de que não há História sem a interpretação do historiador, esse por sua vez constrói a imagem do passado, reelaborando-a nitidamente. $\mathrm{Na}$ perspectiva de Benjamin (s/d), o historiador não tem como objetivo estudar o passado para pensar o futuro, mas sim explodir o "continuum" da História, enquanto acúmulo de ruínas por onde passa livremente o vencedor, libertando assim, as esperanças desse passado, que guarda pela hora messiânica de sua salvação. A salvação proposta pelo autor consiste em evocar a memória que contém o sonho dos oprimidos por um mundo mais fraterno. Assim, salvar é atualizar o passado, realizar suas esperanças, como pode ser visto na Tese VI sobre o conceito de História:

Articular historicamente o passado não significa conhece-lo "como ele de fato foi". Significa apropriar-se de uma reminiscência, tal como ela relampeja no momento de um perigo. Cabe ao materialismo histórico fixar uma imagem do passado, como ele se apresenta, no momento do perigo, ao sujeito histórico, sem que ele tenha consciência disso. O perigo ameaça tanto a existência da tradição como os que a recebem. Para ambos, o perigo é o mesmo: entregar-se às classes dominantes, como seu instrumento. Em cada época, é preciso arrancar a tradição ao conformismo, que quer apoderar-se dela. Pois o Messias não vem apenas como salvador; ele 
vem também como o vencedor do Anticristo. O dom de despertar o no passado as centelhas da esperança é privilégio exclusivo do historiador convencido de que também os mortos não estarão em segurança se o inimigo vencer. E esse inimigo não tem cessado de vencer (BENJAMIN, s/d, p. 224-225 - Grifos nossos).

Portanto, cabe ao historiador decifrar alegoricamente esta História que tem imortalizado a dominação, procurando salvar as suas esperanças, reescrevendo outra história. Benjamin (s/d) afirmava que a tarefa da crítica é revelar os possíveis da História, mostrar que o passado comportava outros futuros não concretizados, ou seja, resgatar aquilo que poderia ter feito com que a história tivesse outro desenrolar. Neste contexto, a Literatura não seria meramente um documento histórico, mas sim uma forma de historiografia não oficial. Portanto, a obra literária corresponderia ao índice de possiblidades não realizadas na história. Neste sentido, afirma Sevcenko (1989, p. 21-22):

\begin{abstract}
A literatura fala ao historiador sobre as histórias que não ocorreram, sobre as possiblidades que não vingaram, sobre os planos que não se concretizaram. Ela é o testemunho triste, porém sublime dos homens que foram vencidos pelos fatos. Mas será que toda a realidade da história se resume aos fatos e ao seu sucesso (...). Segundo outro pensador [Michel Foucault] (...) "o real não se subordina ao possível; o contingente não se opõe ao necessário. Pode-se, portanto, pensar numa história dos desejos não consumados, dos possíveis não realizados, das ideias não consumidas. A produção dessa historiografia teria, por consequência, de se vincular aos grupamentos humanos que ficaram marginais ao sucesso dos fatos. Estranhos ao êxito, mas nem por isso ausentes, eles formaram o fundo humano de cujo abandono e prostração se alimentou a literatura (...). Esse é o caminho pelo qual a literatura se presta como um índice admirável e em certos momentos mesmo privilegiado, para o estudo da história social.
\end{abstract}

Tomamos por base essas ideias e a afirmação de Ruiz (2003, p.77) de que devemos "ensinar aos alunos não a contemplar o 'edifício da História' como algo já pronto, mas (...) ensinarlhes a edificar o próprio edifício” para pensar uma proposta de ensino de História recorrendo ao uso da Literatura, já que por meio da análise desse tipo de fonte seria possível contribuir para que o aluno construísse sua própria concepção de História, construísse conceitos e relacioná-los a diferentes problemáticas. Portanto, a literatura pode favorecer a:

(...) ensinar a selecionar, relacionar e interpretar dados e informações de maneira a ter uma maior compreensão da realidade que estiver sendo estudada; ensinar a construir argumentos que permitam explicar a si próprios e aos outros, de maneira convincente, a apreensão e compreensão da situação histórica; significa, enfim, ensinar a ter uma percepção o mais abrangente possível da condição humana, nas mais diferentes culturas e diante dos mais variados problemas (RUIZ, 2003, p. 78).

Simone Garcia (2002) ${ }^{3}$ em sua obra Canudos: história e literatura propõe, numa perspectiva benjaminiana, que a relação entre a História e a Literatura, por corresponder essa ao índice de possibilidades não realizadas pela História, nos possibilitaria reescrever a História, recuperando sonhos, fantasias e desejos dos excluídos por uma vida melhor, mais justa e fraterna. Permitiria mostrar também que o passado comportava outros possíveis, podados pelo desenvolvimento histórico. Além de, resgatar aquilo que poderia ter feito com que a História tivesse outro desenrolar.

Garcia (2002) esclarece ainda que essa forma de pensar a História como uma obra aberta, passível de várias leituras/interpretações, tem implicações importantes para o ensino de História.

${ }^{3}$ A partir de 2015 devido a seu casamento passou a utilizar o nome de Simone Garcia Almeida 
Segundo a professora, o pensamento artístico é uma forma de representação da realidade rica e extremamente crítica. Mediante a representação estética da vida, deixaríamos de apenas reproduzir uma realidade já dada, para nela interferir a partir de nosso imaginário.

A proposta de trabalhar nessa perspectiva é possibilitar ao estudante de História que possa aprender por meio dessa linguagem, que não precisa ficar preso só ao que "realmente" aconteceu, compreender que é possível repensar, transformar, recriar essa realidade.

Assim sendo, acreditamos que um estudo interdisciplinar que envolva a História e a Literatura possa ser muito frutífero na análise de movimentos sociais, como por exemplo, Canudos, Quilombo dos Palmares, Revolta dos Malês, todos derrotados pela classe dominante. Podemos solicitar aos alunos que produzam textos nos quais eles poderiam reescrever o final dessas histórias, e nessas proposições escrever uma anti-história, colocando nela seus sonhos, desejos, utopias, refletindo, portanto, sobre o passado, seu presente e pensando a sociedade que gostariam de viver no futuro. Esse tipo de reflexão é de suma importância também, por permitir uma articulação pelo estudante entre o passado, o presente e o futuro. Claro que essa perspectiva tem por base a reflexão crítica, pois sabemos da impossibilidade de mudarmos o passado.

Por ser uma proposta que envolve a produção textual, seria necessário a participação também do professor de Língua Portuguesa, o qual poderia dar maiores subsídios sobre os tipos de textos que poderiam ser produzidos, contribuindo para o sucesso do trabalho interdisciplinar.

Desta forma, se faz necessário introduzir aos alunos dos Cursos de Licenciatura em História na utilização de documentos, não só na pesquisa, mas também no ensino de História, haja vista, que estamos formandos profissionais para atuarem no campo educacional.

A partir do exposto, concluímos que o professor deve iniciar seu trabalho com a pesquisa e seleção de Literaturas que tratem e envolvam os temas históricos que pretende ministrar em sala de aula. Em seguida, definir quais temas são possíveis de serem analisados, desenvolver uma proposta de trabalho pautada em objetivos que se pretende atingir e refletir no processo de avaliação do trabalho que será feito pelos alunos. É importante também que o professor busque saber dos estudantes se a metodologia aplicada foi interessante e produtiva para eles. Essa preocupação quanto ao resultado final é o que torna a prática de ensino interdisciplinar mais relevante e dinâmica.

Devemos destacar ainda Correia (2012), a qual pontua a necessidade de revermos o conceito de ensino-aprendizagem, haja vista que as metodologias estão constantemente sendo repensadas, exigindo atualização continuada dos professores, principalmente, quando procuram incorporar em sua prática diferentes fontes para o ensino.

Frente a tudo isso, é importante também que o professor esteja preparado, tendo uma formação pedagógica satisfatória e que consiga criar novas estratégias de ensino e avaliação de seus alunos. Recorremos também a Correia (2012) que orienta sobre a prática educativa do professor:

O professor ao diversificar as fontes e dinamizar a prática de ensino, democratiza o acesso ao saber, possibilita o confronto e o debate de diferentes visões, estimula a incorporação e o estudo da complexidade da cultura e da experiência histórica. Problematizar a história em sala de aula consiste assim em mobilizar conteúdos que não tenham caráter estático, desvinculados no tempo e no espaço, como fins em si mesmos, mas que permitam aos estudantes compararem as situações históricas em seus aspectos espaço - temporais e conceituais, promovendo diversos tipos de relações pelas quais seja possível estabelecerem diferenças e semelhanças entre os contextos, identificarem rupturas e continuidades no movimento histórico e, principalmente, situarem-se como sujeitos da história, porque a compreendem e nela intervém . (CORREIA, 2012, p. 197-198). 
Nessa perspectiva, o professor deixa de ser um mero transmissor de conhecimentos prontos e acabados, para adquirir o papel de orientador participante dentro desse processo de ensino e aprendizagem, auxiliando seus alunos a pensar criticamente a realidade e a defender seus argumentos. Por essa razão, ele também auxilia na formação para a cidadania.

\section{Cosiderações finais}

Para responder às diferentes problemáticas do mundo contemporâneo, tanto no campo da pesquisa, como no do ensino é cada vez mais necessário que procuremos desenvolver um trabalho interdisciplinar, haja vista que determinados temas são melhores compreendidos por meio de duas ou mais áreas do conhecimento. No caso de estudos que envolvam representações passadas e presentes, muitas vezes, a Literatura é um campo indispensável para o historiador e professor de História. Neste sentido, é relevante que as universidades se apresentem efetivamente como locais de produção de conhecimento e atuem com responsabilidade na formação de seus acadêmicos no caminho dos estudos interdisciplinares.

Evidenciamos, a partir das propostas de atividades de ensino apresentadas, que ao trabalharmos com obras literárias é indiscutível compreender a obra tanto pelo contexto social no qual se insere, como também como obra de arte que é, ou seja, refletindo também sobre seus aspectos estéticos. Desta forma, é importante citarmos novamente Capraro (2014, p. 4) quando afirma que é “(...) função do pesquisador [e acrescentamos, do professor de História] compreender como tal contexto social foi incorporado pelo autor e manifestado esteticamente na sua produção artística/literária."

Por fim, já que a Literatura é uma forma de representação social e histórica, o ensino de História, por meio da utilização de fontes literárias, poderá levar os alunos a refletirem sobre as experiências humanas, os hábitos, as atitudes, os sentimentos, as ideologias, as práticas e as inquietações que circulam em cada momento histórico e em diversas sociedades. A partir da Literatura também é possível acessar às expectativas, esperanças e sonhos dos homens e mulheres que fazem parte dessas sociedades. A Literatura permite, deste modo, alcançar percepções e leituras da realidade, por meio do olhar de seus autores, nas quais podemos entrever caminhos, projetos, valores, formas de ser e de sentir. É, portanto, representação do que existe e proposição do que poderia existir.

\section{Referências}

ALMEIDA, Simone Garcia. A representação do negro na literatura brasileira: caminhos para uma discussão sobre educação antirracista. Projeto de Extensão registrado no Departamento de Extensão da Universidade Federal do Amapá, 2017.

BENJAMIN, Walter. Magia e técnica, arte e política. Ensaios sobre a literatura e história da cultura. Obras escolhidas, vol.1, $4^{a}$ ed., São Paulo: Brasiliense, s/d.

BICUDO, Maria Aparecida Viggiani. A pesquisa interdisciplinar: uma possibilidade de construção do trabalho científico/acadêmico. Educ. Mat. Pesqui., São Paulo, v. 10, n. 1, p. 137-150, 2008, BITTENCOURT, Circe Mario Fernandes. Ensino de História: fundamentos e métodos. São Paulo, Cortez, 2004.

BORGES, Valdeci Rezende. História e Literatura: algumas considerações. Revista de Teoria da História. Ano 1, Número 3, p. 94-109, junho/2010. 
CANDIDO. Antônio. Literatura e Sociedade: estudos de teoria e história literária. São Paulo: Queiroz, 2000.

CAPRARO, André Mendes. História e Literatura: proximidades na fronteira. Disponível em: http://www.pgedf.ufpr.br/downloads/Artigos\%20PS\%20Mest\%202014/Andre\%20Capraro/Historia_e_Literatura_-_Andre_Capraro.pdf. Acesso em: [20 out.2017].

CHARTIER, Roger. A história cultural entre práticas e representações. Rio de Janeiro: Bertrand Brasil, 1990.

. A história ou a leitura do tempo. Belo Horizonte: Autêntica, 2009.

CORREIA, Janaína dos Santos. O uso da fonte literária no ensino de História: diálogo com o romance "Úrsula" (final do século XIX). História \& Ensino. Londrina, v. 18, n. 2, p. 179-201, jul./dez. 2012.

GAFFO, Bethânia Cristina. A nova história cultural e a utilização da literatura para a pesquisa historiográfica. Anais do VI Congresso Internacional de História democracia e autoritarismo no mundo contemporâneo, Maringá, 2013, 85-107.

GARCIA. Simone. Canudos: História e Literatura. Curitiba: HD Livros, 2002.

GRECCO, Gabriela de Lima. História e Literatura: entre narrativas literárias e históricas, uma análise através do conceito de representação. Revista Historiador. Porto Alegre, n. 07, ano 07, p. 118129, jan/2015. Disponível em: http://www.historialivre.com/revistahistoriador. Acesso em: [11 nov.2017].

LE GOFF, Jacques. História e Memória. Campinas: EdUNICAMP, 1990.

LIMA, Aline Cristina da Silva; AZEVEDO, Crislane Barbosa. A interdisciplinaridade no Brasil e no ensino de história: um diálogo possível. Revista Educação e Linguagens. Campo Mourão, v. 2, n. 3 , p. 128-150, jul./dez. 2013.

MORAES, Dislane Zerbinatti. Literatura e História na escola: aprendizagens e desafios mútuos. Anais do SILEL.. Uberlândia: EDUFU, v. 1, 2009, p. 01-09.

PACHECO, Roberto Carlos dos Santos; TOSTA, Kelly Cristina Benetti Tonani; FREIRE, Patricia de Sá. Interdisciplinaridade vista como um processo complexo de construção do conhecimento: uma análise do Programa de Pós-Graduação EGC/UFSC. R.B.P.G., Brasília, v. 7, n. 12, p. 136 - 159, jul. 2010.

PÁTARO, Ricardo Fernandes; BOVO, Marcos Clair. A interdisciplinaridade como possibilidade de diálogo e trabalho coletivo no campo da pesquisa e da educação. Revista NUPEM, Campo Mourão, v. 4, n. 6, p. 45-63, jan./jul. 2012.

PESAVENTO, Sandra Jatahy. História \& literatura: uma velha-nova história. Nuevo Mundo Mundos Nuevos, jan./fev 2006. Disponivel em: http://nuevomundo.revues.org/index1560.html. Acesso em [10 out./2017].

. Fronteiras da ficção: diálogos da História com a Literatura. In: NODARI, Eunice; PEDRO Joana Maria; LOKOI, Zilda Gricoli (orgs.). História: Fronteiras. Vol. II. São Paulo: Humanitas, p. 819831, 1999.

. História e história cultural. Belo Horizonte: Autêntica, 2004.

RUIZ, Rafael. Novas formas de abordar o ensino de história. In: KARNAL, Leandro (org.). História na sala de aula: conceitos, práticas e propostas. São Paulo: Contexto, 2003, p. 75-94.

SENA JUNIOR, Gilberto Ferreira. Realidade versus ficção: a literatura como fonte para a escrita da História. (s/d), p. 01-12. .Disponivel em: http://www.historia.uff.br/estadoepoder/6snepc/GT13/ GT13-GILBERTO.pdf. Acesso em: [08 out. 2017].

SEVCENKO, Nicolau. Literatura como missão. Tensão social e criação cultural na Primeira República. $3^{a}$ ed., São Paulo: Brasiliense, 1999. 
SILVA, Luiza Helena Oliveira da; PINTO, Francisco Neto Pereira. Interdisciplinaridade: as práticas possíveis. Revista Querubim - revista eletrônica de trabalhos científicos - Letras, Ciências Humanas e Ciências Sociais, Ano 5, p. 01-18, 2009.

SILVA, Wagner Rodrigues. Construção da interdisciplinaridade no espaço complexo de ensino e pesquisa. Cadernos de Pesquisa, v.41, n.143, , p. 582- 605, mai/ago, 2011

VIEIRA, Maria do Pilar A.; PEIXOTO, Maria do Rosário da C.; KHOURY, Yara Maria Aun. A pesquisa em história. São Paulo: Ática, 2007.

THIESEN, Juares da Silva. A interdisciplinaridade como movimento articulador no processo ensinoaprendizagem. Revista Brasileira de Educação, v. 13, n. 39, p.545-598, set./dez. 2008.

XAVIER, Erica da Silva; CUNHA, Maria de Fátima da. Ensino e História: o uso das fontes históricas como ferramentas na produção de conhecimento histórico. (s/d), p. 639-654. Disponível: http://www.uel.br/eventos/sepech/sumarios/temas/ensino_e_historia_o_uso_das_fontes_historicas_como_ferramentas_na_producao_de_conhecimento_historico.pdf. Acesso em [26 nov. 2017]. 